\title{
Incidence of Pedestrian Traffic Injury in Sao Paulo Brazil
}

\author{
Washington Gomes de Araujo, Rodrigo Tadashi Martines*, Tamiris Pontel de Oliveira, \\ Priscila Souza Schinzari, Jane de Eston Armond
}

Department of Collective Health, School of Medicine, University of Santo Amaro, Sao Paulo, Brazil

Email address:

tdmartines@yahoo.com (R. T. Martines)

${ }^{*}$ Corresponding author

\section{To cite this article:}

Washington Gomes de Araujo, Rodrigo Tadashi Martines, Tamiris Pontel de Oliveira, Priscila Souza Schinzari, Jane de Eston Armond. Incidence of Pedestrian Traffic Injury in Sao Paulo Brazil. Journal of Surgery. Vol. 7, No. 1, 2019, pp. 19-23. doi: 10.11648/j.js.20190701.14

Received: February 17, 2019; Accepted: March 26, 2019; Published: April 18, 2019

\begin{abstract}
Pedestrian traffic injuries represent an important cause of mortality, and although the occurrence rates are lower than collisions between vehicles, the lethality is much higher due to the vulnerability of the pedestrians. This study characterized the victims of traffic accidents as to gender, age group, period of occurrence, association with alcohol and drug use, place of accidents, diagnosis of attendance, evolution of victims and types of vehicles involved, in order to assist public managers in intervening in such scenario. It is a cross-sectional, quantitative, descriptive and retrospective epidemiological study of 2719 pedestrians injured in traffic accident records, during 2017 in Sao Paulo, Brazil. Men were involved in $61.9 \%$ of the traffic accidents and the most affected age group was between 20 and 24 years $(12.4 \%)$. The highest incidence was in the afternoon (12.2\%), in the South region (4.5\%) and 46.3\% associated with cars. The lower limb traumas were the most frequent $(32.3 \%)$ and $76.5 \%$ of the victims followed to hospital discharge. This study revealed the importance of the epidemiological analyses of traffic accidents. It is an important tool to guide governments to promote public and drivers education to respect the traffic regulations. And besides, it can be used to manage the assistance of the pedestrian victims of traffic accidents by the maintaining of the pre-hospital and hospital care teams in strategic locations to minimize the time between the accident and the victim's care by the public Brazilian National Health System (Sistema Único de Saúde - SUS).
\end{abstract}

Keywords: Pedestrians, Traffic Accidents, Wounds and Injuries, Multiple Trauma, Automobile Driving, Cross-Sectional Studies

\section{Introduction}

In the last decades, the advance of automobile industries has generated numerous urban and social transformations that have contributed to the growth of the cities. However, in many cases this growth has been occurred in a disorderly way and without adequate infrastructure to accommodate the expansion of the vehicle fleet. Linked to unsatisfactory conditions of public transportation, that can be observed in many cities in Brazil, there is increasing of the number of individual transportation, that result in even more chaotic traffic in big cities [1].

Pedestrian traffic injuries represent an important cause of mortality, and although the occurrence rates are lower than collisions between vehicles, the lethality is much higher due to the vulnerability of the pedestrians [2]. In addition, there is a high degree of disability with emotional and social impacts [3]. Traffic accidents are a serious public health problem associated with drivers and pedestrians behavioral factors, vehicle safety and precarious urban space. In Brazil, annual expenses with traffic accidents are approximately $\mathrm{R} \$ 28$ billion. According to the World Health Organization (WHO), there are 1.3 million deaths from traffic accidents in the world annually and about 2050 million people are injured [2, 4-8]. In this country 8,200 traffic accidents with pedestrians were recorded in 2013, which is equivalent to a rate of 4.1 per 100,000 inhabitants. Among the reasons for traffic injuries and deaths are structural factors such as roads and urban lanes maintenance, increased fleet of vehicles, use of alcohol associated with driving and non-use of safety equipment [9]. Due to the vulnerability of pedestrians, the traffic accidents represent an important cause of morbidity and mortality in Brazil [10]. Some groups are more vulnerable, including pedestrians, bikers and motorcyclists. They suffer more serious injuries in multiple organs. Pedestrians are still the ones with the highest morbidity and mortality $[7-8,11]$. 
Studies indicate that countries where have been implemented traffic regulations, enforcement and education have demonstrated lower death rates [12]. Considering all above conditions, Brazil has implemented some laws to regulate traffic and reduce accidents, such as the Brazilian National Traffic Code in 1998 and the severe Driving Under Influence Law in 2008 , in addition to improving the vehicle safety, the electronic speed and the traffic control. However, traffic accidents are still responsible for a high mortality rate $[6,8]$.

Faced with the challenges of reducing the number of traffic accidents and their social consequences, and for adequacy of pre-hospital and hospital care of trauma in the city of Sao Paulo, Brazil, the aim of this study was to characterize the pedestrians injured in traffic accident in regard to gender, age, period of occurrence, association with alcohol and drug use, location of accidents, trauma diagnosis, medical evolution of the victims and vehicles involved, in order to guide the government in urban and hospital development strategies.

\section{Methods}

This is a cross-sectional, quantitative, descriptive and retrospective epidemiological study of pedestrians injured in traffic accident records, during 2017 in the city of Sao Paulo, state of Sao Paulo, Brazil.

Secondary data was collected on April 17, 2018 through the Information System for Surveillance of Violence and Accidents (SIVVA) of São Paulo city, managed by the Health Surveillance Coordination of the Municipal Health Secretariat of São Paulo (COVISA- SMS) along with the Health Surveillance Supervisors (SUVIS). Notifications of traffic accidents involving pedestrians during the period from
January 1, 2017 to December 31, 2017 were analyzed.

The study population consisted of 2.719 pedestrian victims of traffic accidents. The variables were distributed as follows: characteristics of victims regarding gender (male and female), age group (in years), alcohol and drug use and main diagnoses associated with run over, characteristics of occurrences regarding the time of day (morning, afternoon and night), urban area (north, south, east, west, southeast and center) and the vehicle types (motor vehicles, motorcycles, bicycles, heavy vehicles and others) involved.

After collecting data, they were tabulated and processed in EXCEL software. Subsequently, descriptive statistical analyses were performed, calculating the absolute and relative frequencies of variables.

As recommended by Resolution 466/12 of the National Health Council (CNS), this work exempts approval of the University's Ethics Committee, since secondary information was used and available in a public domain database.

\section{Results}

Between January 1 and December 31, 2017, according to SIVVA data, there were 2.719 road accidents in the city of São Paulo. Of these, 1.684 (61.9\%) were men, while 1.035 (38.1\%) were women. When considering the most affected age groups, it was observed that the most road accidents occurred for those who were 20 to 24 years old, 335 (12.4\%), between 15 and 19 years was the second most affected with $318(11.6 \%)$, and between 10 and 14 , there were about $237(8.7 \%)$ of the total number of road accidents. Concerning the abuse of licit substances, $68(2.5 \%)$ pedestrians were under the influence of alcohol, while $12(0.4 \%)$ were under influence of illicit substances (Table 1).

Table 1. Distribution of pedestrian victims of traffic accident, according to age, gender, alcohol and drug use in Sao Paulo, 2017.

\begin{tabular}{|c|c|c|c|c|c|c|c|c|c|}
\hline $\begin{array}{l}\text { AGE } \\
\text { (years) }\end{array}$ & $\begin{array}{l}\text { Female } \\
\text { N (\%) }\end{array}$ & $\begin{array}{l}\text { Male } \\
\text { N (\%) }\end{array}$ & $\begin{array}{l}\text { Alcohol (+) } \\
\text { N }(\%)\end{array}$ & $\begin{array}{l}\text { Alcohol (-) } \\
\text { N (\%) }\end{array}$ & $\begin{array}{l}\text { Alcohol } \\
\text { Ignored } \\
\text { N }(\%)\end{array}$ & $\begin{array}{l}\text { Drugs (+) } \\
\text { N (\%) }\end{array}$ & $\begin{array}{l}\text { Drugs (-) } \\
\text { N (\%) }\end{array}$ & $\begin{array}{l}\text { Drugs } \\
\text { Ignored } \\
\text { N }(\%)\end{array}$ & $\begin{array}{l}\text { TOTAL } \\
\text { N (\%) }\end{array}$ \\
\hline $0 \mathrm{a} 4$ & $57(2.1)$ & $117(4.3)$ & $0(0.0)$ & $58(2.1)$ & $116(4.3)$ & $0(0.0)$ & $58(2.1)$ & $116(4.3)$ & $174(6.4)$ \\
\hline 5 a 9 & $63(2.3)$ & $155(5.7)$ & $1(0.0)$ & $62(2.3)$ & $155(5.7)$ & $0(0.0)$ & $63(2.3)$ & $155(5.7)$ & $218(8.0)$ \\
\hline 10 a 14 & $85(3.1)$ & $152(5.6)$ & $0(0.0)$ & $77(2.8)$ & $160(5.9)$ & $0(0.0)$ & $76(2.8)$ & $161(5.9)$ & $237(8.7)$ \\
\hline 15 a 19 & $140(5.1)$ & $178(6.5)$ & $6(0.2)$ & $98(3.6)$ & $214(7.9)$ & $1(0.0)$ & $102(3.8)$ & $215(7.9)$ & $318(11.7)$ \\
\hline 20 a 24 & $124(4.6)$ & $211(7.8)$ & $13(0.5)$ & $91(3.3)$ & $231(8.5)$ & $2(0.1)$ & $92(3.4)$ & $241(8.9)$ & $335(12.3)$ \\
\hline 25 a 29 & $55(2.0)$ & $121(4.5)$ & $4(0.1)$ & $45(1.7)$ & $127(4.7)$ & $2(0.1)$ & $48(1.8)$ & $126(4.6)$ & $176(6.5)$ \\
\hline 30 a 34 & $57(2.1)$ & $108(4.0)$ & $8(0.3)$ & $61(2.2)$ & $96(3.5)$ & $1(0.0)$ & $64(2.4)$ & $100(3.7)$ & $165(6.1)$ \\
\hline 35 a 39 & $70(2.6)$ & $110(4.0)$ & $8(0.3)$ & $64(2.4)$ & $108(4.0)$ & $1(0.0)$ & $68(2.5)$ & $111(4.1)$ & $180(6.6)$ \\
\hline 40 a 44 & $43(1.6)$ & $108(4.0)$ & $6(0.2)$ & $40(1.5)$ & $105(3.9)$ & $3(0.1)$ & $44(1.6)$ & $104(3.8)$ & $151(5.6)$ \\
\hline 45 a 49 & $42(1.5)$ & $84(3.1)$ & $3(0.1)$ & $29(1.1)$ & $94(3.5)$ & $0(0.0)$ & $31(1.1)$ & $95(3.5)$ & $126(4.6)$ \\
\hline 50 a 54 & $66(2.4)$ & $70(2.6)$ & $10(0.4)$ & $35(1.3)$ & $91(3.3)$ & $2(0.1)$ & $37(1.4)$ & $97(3.6)$ & $136(5.0)$ \\
\hline 55 a 59 & $47(1.7)$ & $63(2.3)$ & $3(0.1)$ & $31(1.1)$ & $76(2.8)$ & $0(0.0)$ & $33(1.2)$ & $77(2.8)$ & $110(4.0)$ \\
\hline 60 a 64 & $55(2.0)$ & $57(2.1)$ & $5(0.2)$ & $36(1.3)$ & $71(2.6)$ & $0(0.0)$ & $38(1.4)$ & $74(2.7)$ & $112(4.1)$ \\
\hline 65 a 69 & $48(1.8)$ & $56(2.1)$ & $1(0.0)$ & $35(1.3)$ & $68(2.5)$ & $0(0.0)$ & $35(1.3)$ & $69(2.5)$ & $104(3.8)$ \\
\hline 70 a 74 & $30(1.1)$ & $32(1.2)$ & $0(0.0)$ & $24(0.9)$ & $38(1.4)$ & $0(0.0)$ & $25(0.9)$ & $37(1.4)$ & $62(2.3)$ \\
\hline 75 a 79 & $26(1.0)$ & $21(0.8)$ & $0(0.0)$ & $16(0.6)$ & $31(1.1)$ & $0(0.0)$ & $16(0.6)$ & $31(1.1)$ & $47(1.7)$ \\
\hline 80 a 84 & $12(0.4)$ & $22(0.8)$ & $0(0.0)$ & $9(0.3)$ & $25(0.9)$ & $0(0.0)$ & $9(0.3)$ & $25(0.9)$ & $34(1.3)$ \\
\hline 85 a 89 & $9(0.3)$ & $14(0.5)$ & $0(0.0)$ & $6(0.2)$ & $17(0.6)$ & $0(0.0)$ & $6(0.2)$ & $17(0.6)$ & $23(0.8)$ \\
\hline 90 e + & $5(0.2)$ & $5(0.2)$ & $0(0.0)$ & $3(0.1)$ & $7(0.3)$ & $0(0.0)$ & $3(0.1)$ & $7(0.3)$ & $10(0.4)$ \\
\hline branco/ignorado & $1(0.0)$ & $0(0.0)$ & $0(0.0)$ & $0(0.0)$ & $1(0.0)$ & $0(0.0)$ & $0(0.0)$ & $1(0.0)$ & $1(0.0)$ \\
\hline TOTAL & $1035(38.1)$ & $1684(61.9)$ & $68(2.5)$ & $820(30.2)$ & $1831(67.3)$ & $12(0.4)$ & $848(31.2)$ & $1859(68.4)$ & $\begin{array}{l}2719 \\
(100.0)\end{array}$ \\
\hline
\end{tabular}

Source: Violence and Accident Surveillance Information System (SIVVA) - Health Surveillance Coordination of the Municipal Health Secretary of Sao Paulo (COVISA - SMS) - Health Surveillance Supervisors (SUVIS). 
When observing the distribution of traffic accidents by periods and regions of occurrences in the city of São Paulo in Table 2, it was observed that the period of highest incidence was the afternoon (from 1:00 pm to 6:59 p.m.) with 332 (12.2\%), followed by the night shift (from 07:00 pm to $12: 59$ am) with $179(6.6 \%)$; in the early morning (from 1:00 am to $6: 59 \mathrm{am})$, there were $164(6.0 \%)$ traffic accidents and (5.9\%). However, it is worth pointing out that in $1883(69.3 \%)$ cases, the day period was ignored or the data was not filled in. Concerning the regions where there were more occurrences, the Southern region concentrated the majority of these with $121(4.5 \%)$, and subsequently was the Southeast with 85 (3.1\%), followed by the Eastern region with 81 (3.0\%), West with $36(1.3 \%)$, North with $32(1.2 \%)$ and finally the Center with $6(0.2 \%)$. It is noteworthy that in $2.358(86.7 \%)$ of those traffic accidents, this data was not filled or ignored.

Table 2. Distribution of traffic accidents with pedestrians by periods and urban areas of occurrences in Sao Paulo, 2017.

\begin{tabular}{|c|c|c|c|c|c|c|c|c|}
\hline Period / Urban area & $\begin{array}{l}\text { Central } \\
\mathrm{N}(\%)\end{array}$ & $\begin{array}{l}\text { East } \\
\text { N (\%) }\end{array}$ & $\begin{array}{l}\text { North } \\
\text { N (\%) }\end{array}$ & $\begin{array}{l}\text { Southeast } \\
\text { N (\%) }\end{array}$ & $\begin{array}{l}\text { South } \\
\text { N (\%) }\end{array}$ & $\begin{array}{l}\text { West } \\
\text { N (\%) }\end{array}$ & $\begin{array}{l}\text { Ignored } \\
\text { N }(\%)\end{array}$ & $\begin{array}{l}\text { TOTAL } \\
\text { N }(\%)\end{array}$ \\
\hline Morning 7am $-12: 59 \mathrm{pm}$ & $2(0.1)$ & $11(0.6)$ & $6(0.2)$ & $11(0.4)$ & $14(0.5)$ & $7(0.3)$ & $110(4.0)$ & $161(5.9)$ \\
\hline Afternoon $1 \mathrm{pm}-6: 59 \mathrm{pm}$ & $2(0.1)$ & $23(0.8)$ & $13(0.5)$ & $23(0.8)$ & $37(1.4)$ & $10(0.4)$ & $224(8.2)$ & $332(12.2)$ \\
\hline Evening 7pm - 12:59am & $1(0.0)$ & $16(0.6)$ & $3(0.1)$ & $7(0.3)$ & $28(1.0)$ & $7(0.3)$ & $117(4.3)$ & $179(6.6)$ \\
\hline Early hours $1 \mathrm{am}-6: 59 \mathrm{am}$ & $0(0.0)$ & $13(0.5)$ & $3(0.1)$ & $16(0.6)$ & $10(0.4)$ & $6(0.2)$ & $116(4.3)$ & $164(6.0)$ \\
\hline Blank/ Ignored & $1(0.0)$ & $18(0.7)$ & $7(0.3)$ & $28(1.0)$ & $32(1.2)$ & $6(0.2)$ & $1791(65.9)$ & $1883(69.3)$ \\
\hline TOTAL & $6(0.2)$ & $81(3.0)$ & $32(1.2)$ & $85(3.1)$ & $121(4.5)$ & $36(1.3)$ & $2358(86.7)$ & $2719(100.00)$ \\
\hline
\end{tabular}

Source: Violence and Accident Surveillance Information System (SIVVA) - Health Surveillance Coordination of the Municipal Health Secretary of Sao Paulo (COVISA - SMS) - Health Surveillance Supervisors (SUVIS).

Table 3. Distribution of types of vehicles involved in traffic accidents with pedestrians in Sao Paulo, 2017.

\begin{tabular}{ll}
\hline Type of Vehicle & Notifications N (\%) \\
\hline Car & $1259(46.3)$ \\
Motorcycle & $648(23.8)$ \\
Bicycle & $138(5.1)$ \\
Bus/Truck/Other & $128(4.7)$ \\
Subway or Train & $7(0.3)$ \\
Air Transport & $1(0.0)$ \\
Other & $28(1.0)$ \\
Blank or Ignored & $516(19.0)$ \\
TOTAL & $2719(100.0)$ \\
\hline
\end{tabular}

Source: Violence and Accident Surveillance Information System (SIVVA) Health Surveillance Coordination of the Municipal Health Secretary of Sao Paulo (COVISA - SMS) - Health Surveillance Supervisors (SUVIS).

Regarding the type of vehicle involved in traffic accidents, according to Table 3, automobiles correspond for almost half this total representing $1,259 \quad(46.3 \%)$, followed by motorcycles with 648 (23.8\%), bicycles 138 (5.1\%), heavy vehicles (buses, trucks or others) $128(4.7 \%)$, subway or train $7(0.3 \%)$, air transport $1(0,0)$, other $28(1.0 \%)$, and finally blank or ignored $516(19.0 \%)$.

Regarding the types of injuries, according to Table 4, the main diagnoses of victims of traffic accidents were categorized according to the International Classification of Diseases (ICD-10) and separated by anatomical region. It was observed that lower limb trauma was the most injured area with $877(32.3 \%)$ in pedestrians, whereas other uninformed diagnoses represented 684 (25.1\%), lesions of head and neck were the third most frequently affected place with $575(21.1 \%)$, followed by upper limb lesion with 398 $(14.6 \%)$, abdomen, dorsum and pelvis corresponding to 67 $(2.5 \%)$, thorax $66(2.4 \%)$ and finally blank or ignored with $52(2 \%)$.

Table 4. Main diagnosis of trauma in pedestrian victims of traffic accidents in São Paulo, 2017.

\begin{tabular}{lll}
\hline ICD 10 and Diagnosis & N (\%) & N (\%) Anatomical Region \\
\hline Head and Neck & 127 & $575(21.1)$ \\
S09.9 Unspecified injury of face and head & 88 \\
S00.9 Superficial injury of unspecified part of head & 360 \\
Other ICDs of head and neck & 21 \\
Thorax & 16 \\
S20.2 Contusion of thorax & 29 \\
S20.8 Superficial injury of other and unspecified parts of thorax & \\
Other ICDs of thorax region & 23 \\
Abdomen, back and pelvis & 15 \\
S30.0 Contusion of lower back and pelvis & 29 \\
S30.9 Superficial injury of abdomen, lower back and pelvis, part unspecified & \\
Other ICDs of abdomen, lower back and pelvis & 46 \\
Upper limbs & 40 \\
S40.0 Contusion of shoulder and upper arm & $25.4)$ \\
S60.2 Contusion of other parts of wrist and hand & 24 \\
S40.9 Superficial injury of shoulder and upper arm, unspecified & 24 \\
S50.0 Contusion of elbow & 263 \\
Other ICDs of upper limbs & \\
Lower limbs & 73 \\
S80.0 Contusion of knee & $67.5)$ \\
\hline
\end{tabular}




\begin{tabular}{lll}
\hline ICD 10 and Diagnosis & N (\%) & N (\%) Anatomical Region \\
\hline S90.0 Contusion of ankle & 71 \\
Other ICDs of lower limbs & 733 \\
Other diagnosis & & \\
T07 Unspecified multiple injuries & 176 & \\
T00.9 Multiple superficial injuries, unspecified & 145 \\
T14.9 Unspecified injuries & 100 & $684(25.1)$ \\
Other ICDs of unspecified region & 263 \\
Blank & 52 & $52(2.0)$ \\
TOTAL & 2719 & $2719(100.0)$ \\
\hline
\end{tabular}

Source: Violence and Accident Surveillance Information System (SIVVA) - Health Surveillance Coordination of the Municipal Health Secretary of Sao Paulo (COVISA - SMS) - Health Surveillance Supervisors (SUVIS)

In the analysis of the evolution of traffic accident victims, according to Table 5, 2,080 (76.5\%) obtained hospital discharge, while $172(6.3 \%)$ were transferred to other health services, $128(4.7 \%)$ required hospitalization, $16(0.6 \%)$ were received in death, or died during the care.

Table 5. Medical evolution of the victims of traffic accidents in Sao Paulo in 2017

\begin{tabular}{ll}
\hline Medical evolution & N (\%) \\
\hline Follow up & $20(0.7)$ \\
Discharge & $2080(76.5)$ \\
Observation & $117(4.3)$ \\
Hospitalization & $128(4.7)$ \\
Received in Death & $5(0.2)$ \\
Transferred & $172(6.3)$ \\
Death in care & $11(0.4)$ \\
Blank or Ignored & $186(6.8)$ \\
TOTAL & $2719(100.0)$ \\
\hline
\end{tabular}

Source: Violence and Accident Surveillance Information System (SIVVA) Health Surveillance Coordination of the Municipal Health Secretary of Sao Paulo (COVISA - SMS) - Health Surveillance Supervisors (SUVIS).

\section{Discussion}

Traffic is a social problem. At each intersection, you can see pedestrians, cars, buses and bicycles that come and go from different directions. The driver wants fluid vehicle traffic, the pedestrian needs less fluidity and the trader wants customers to park in front of his business. Therefore, the interests of the people participating in traffic are not the same and are often conflicting. Independent of individual interests the responsibilities in traffic should be shared among public agencies, drivers and pedestrians [13].

According to WHO data, with the high worldwide mortality rate due to traffic accidents, there is also a high rate of non-fatal injuries with a subgroup of victims with some physical or psychological disability [14]. Faced with this scope, the United Nation decreed, in 2011, the Decade of Action for Traffic Safety in order to prevent traffic accidents. In Brazil, Yellow May movement was a proposal to make the society pay attention to the large numbers of deaths and injuries in traffic.

With high rates of pedestrian accidents, financial losses should be considered. In addition to high costs to the Brazilian National Health System (Sistema Único de Saúde SUS) to victims of accidents, there are also individual losses with reduced labor productivity and physical and psychological sequel for a long period or even for a lifetime [14].

When observing the number of pedestrian victims of traffic accidents in 2017 in São Paulo, the group that involves children and adolescents (0 and 19 years old) had 947 $(34.8 \%)$ people affected. From this data, it can be emphasized that the age group mentioned had a lower perception of danger and the younger ones had less knowledge of traffic laws [15]. Based on these figures, it was observed that men accounted for the majority of victims in the age group between 15 and 19 with $55.9 \%$ of the cases. When analyzing the total number of victims, males represented $61.9 \%$ of pedestrian accidents. This data corroborates with WHO that traffic accidents are one of the main causes of death in male adolescents aged 15 to 19 years old [16]. In this way, these figures reflect a reality not only in Sao Paulo but also worldwide. It is believed that the predominance of male victims is related to the cultural and social behavior of a greater risk exposure of this group when compared with the attitudes of women.

The period with the highest incidence of traffic accidents was the afternoon (from 01:00 pm to $06: 59 \mathrm{pm}$ ) with 332 $(12.2 \%)$ cases. This can be explained by a greater circulation of people. In this period, there is an increased flow of school children through the streets due to the end of classes and workers who have left their work activities. It is possible that in this period, serious accidents occur, often related to traffic without congestion, providing higher car speeds and consequently greater impact $[17,18]$. According to data analyzed, there is little relation between accidents and use of alcohol and illicit drugs, with only $2.5 \%$ of pedestrians using alcohol and $0.4 \%$ using illegal drugs.

Cars and motorcycles were the vehicles most involved in traffic accidents. Together, they account for $70 \%$ of events. This finding relates to the fact that they represent a large part of the fleet of vehicles in Sao Paulo, according to the Brazilian Institute of Geography and Statistics (IBGE) [19]. Due to the greater vulnerability of pedestrians to these types of vehicles, the importance of traffic education on the part of vehicle drivers and pedestrians must be reinforced in order to comply with the applicable laws. Given the high incidence of pedestrian accidents and morbidity and mortality, it suggests the installation of more stringent punishments for offenders in order to reduce accident rates with victims.

Regarding the types of injuries, it is observed that there is 
a predominance of injuries and multiple traumas. Certainly, the disproportionate force between pedestrians and cars is the main cause of the seriousness of the accident victims' injuries. Despite the fragility of pedestrians, of the total occurrences in $2017,76.5 \%$ evolved to hospital discharge and only $0.6 \%$ to death. However, it must be remembered that car accidents represent a great social and financial psychological impact. About 7 billion dollars are spent annually in Brazil due to pre-hospital, rehabilitation and removals from work activities with victims of traffic accidents [18]. All negative outcomes can be avoided through awareness and education in traffic.

\section{Conclusion}

Based on the above considerations, it is possible to infer that awareness and respect for traffic laws are essential to reducing the number of pedestrian accidents. This study revealed the importance of the epidemiological analyses of traffic accidents. It is an important tool to guide governments to promote public and drivers education to respect the traffic regulations. And besides, it can be used to manage the assistance of the pedestrian victims of traffic accidents by the maintaining of the pre-hospital and hospital care teams in strategic locations to minimize the time between the accident and the victim's care by the public Brazilian National Health System (Sistema Único de Saúde - SUS).

\section{References}

[1] Nunes MN, Nascimento LFC. Spatial analysis of deaths due to traffic accidents, before and after the Brazilian Drinking and Driving Law, in micro-regions of the state of São Paulo, Brazil. Rev Assoc Med Bras. 2012; 58 (6): 685-690.

[2] Moreno NTS, Dalmas JS, Martins EAP. Run over: Epidemiological analysis of the last four years. Cienc Cuid Saude. 2016; 15 (4): 693-700.

[3] Anjos KC, Evangelista MRB, Silva JS, Zumiotti AV. A patient victim of car traffic violence: na analysis of socioeconomic profile, accident characteristics and social services intervention in the emergency room. Acta Ortop Bras. 2007; 15 (5): 262-266.

[4] Neto OLD, Montenegro MDMS, Monteiro RA, Júnior JBS, Silva MMAD, Lima, CMD, Júnior JBDS. Mortality due to Road Traffic Accidents in Brazil in the last decade: trends and risk clusters. Cienc Saude Colet. 2012; 17 (9): 2223-2236.

[5] Soares LS, Sousa DACM, Machado ALG, Silva GRF. Profile of trauma victims from motorcycle accidents assisted in a public hospital. Rev Enferm UERJ. 2015; 23 (1): 115-121.

[6] Andrade SSSCDA, Jorge MHPDM. Estimate of physical sequelae in victims of road traffic accidents hospitalized in the Public Health System. Rev Bras Epidemiol. 2016; 19 (1): 100111.
[7] Viégas MLC, Pereira ELR, Targino AA, Furtado VG, Rodrigues DB. Traumatic brain injury in a reference hospital in Para, Brazil: prevalence of victims about gender, age group, mechanisms of trauma, and death. Arq Bras Neurocir. 2013; 32 (01): $15-18$.

[8] Leon LM, Belon AP, Barros MB, Almeida SD, Restitutti MC. Trends in traffic accidents in Campinas, São Paulo State, Brazil: the increasing involvement of motorcyclists. Cad Saúde Pública. 2012; 28 (1): 39-51.

[9] National Health Plan (PNS): 2016 - 2019. Brasilia: Ministry of Health of Brazil. Executive Secretary. Secretary of Planning and Budget, 2016-2019. http://bvsms.saude.gov.br/bvs/publicacoes/plano_nacional_sau de_2016_2019_30032015_final.pdf (March 25th 2019, last access).

[10] Camargo ABM. Senior and mortality: worrying relationship with external causes. SEADE 1st Analysis. Sao Paulo: State Data Analysis System Foundation. 2016; 35: 1-20. http://www.seade.gov.br/wpcontent/uploads/2016/03/Primeira_Analise_35_fev16.pdf (March 25th, 2019, last access).

[11] Soares RAS, Pereira APDJT, Moraes RMD, Vianna RPDT. Characterization of victims of traffic accidents attended by the Mobile Emergency Service in João Pessoa-PB in 2010. Epidemiol Serv Saúde. 2012; 21 (4): 589-600.

[12] Paixão LMMM, Gontijo ED, Mingoti SA, Costa DAS, Friche AAL, Caiaffa WT. Deaths in urban traffic: qualification and information of vulnerable groups. Cad Saúde Pública. 2015; 31: S1-S15.

[13] Rozestraten, Reinier JA. Social Psychology and Traffic. Psychology: Science and profession. 1986; 6 (2): 22-23.

[14] World Health Organization. Global Status Report on Road Safety - 2015. Geneva: World Health Organization, 2018. Available https://apps.who.int/iris/bitstream/handle/10665/277370/WHO -NMH-NVI-18.20-eng.pdf?ua=1 (March 25th, 2019, last access).

[15] Jorge MHPM, Martins CBG. Child, teenager, and traffic: some importante considerations. Assoc Med Bras. 2013; 59 (3): 199-208.

[16] Gorios C, Souza RM, Gerolla V, Maso B, Rodrigues CL, Armond JE. Transport accidents among children and adolescents at the emergency service of a teaching hospital in the southern zone of the city of São Paulo. Rev Bras Ortop. 2014; 49 (4): 391-395.

[17] Almeida RLF, Filho JGB, Macedo MCM, Silva KA, Braga JU, Magalhaes FB. Man, road and vehicle: risk factors associated with the severity of traffic accidents. Rev Saude Publica. 2013; 47 (4): 718-731.

[18] Martines, R. T., Araujo, W. G. D., Rodrigues, C. L., Armond, J. D. E.. Incidence of pedestrian traffic injury in São Paulo, Brazil, in 2016. Acta Ortop Bras. 2018; 26 (2): 112-116.

[19] Brazilian Institute of Geography and Statistics - IBGE. Infographic: municipal fleet of vehicles in São Paulo. 2019. Available at https://cidades.ibge.gov.br/brasil/sp/saopaulo/pesquisa/22/28120 (Last access: March 25th, 2019). 